\title{
Comparison on soil organic carbon and nitrogen dynamics between urban impervious surfaces and vegetation
}

\author{
Xiaolin $\mathrm{Dou}^{1}$, Meng $\mathrm{Lu}^{2}$, and Liding $\mathrm{Chen}^{3}$ \\ ${ }^{1}$ Chinese Academy of Sciences \\ ${ }^{2}$ Yunnan University \\ ${ }^{3}$ Research Center For Eco-Environmental Sciences, Chinese Academy of Sciences
}

February 14, 2021

\begin{abstract}
The soil carbon $(\mathrm{C})$ and nitrogen $(\mathrm{N})$ dynamic was usually considered as a minor change based on a static process in the sealed soil under decades of impervious surface (IS). However, no systematic studies concerning the soil organic carbon (SOC) and nitrogen (SON) dynamic were conducted under IS in contrast with urban vegetation (i.e., forest, grass). Here we utilized fractional distillation of soils as well as stable isotopic analysis to examine soil C\&N cycles after 20 and 30 years of vegetation planting and IS construction in Guangzhou and Shenzhen, Pearl River Delta, China. Soil samples including bare soil (CK) and four land use treatments were split into different chemical fractions. Then we analyzed the $\mathrm{C} \& \mathrm{~N}$ content, $\mathrm{C} / \mathrm{N}$ ratio, $\delta 13 \mathrm{C}$, $\delta 15 \mathrm{~N}, \mathrm{C} \& \mathrm{~N}$ recalcitrant indices (RIC, RIN), and the mean residence time (MRT). We found that the soil C\&N increased first (i.e., 20 years) because of enhanced C\&N stocks in both labile (LP) and recalcitrant pool (RP), and then stabilized or decreased (i.e., 30 years) with the IS ages in both cities. IS had a lower SOC decomposition rate and thus resulted in the five to ten times longer MRT (about 259-465 years) than that in vegetated soils (about 39-55 years). Moreover, the SOC\&SON always showed a decoupling relation in labile pools (i.e., LC and LN) in forests in both cities. The study showed the IS remarkably altered the soil C\&N dynamics, showing a great difference in SOC\&SON fractions composition and turnover compared with vegetation.
\end{abstract}

\section{Hosted file}

Manuscript-LAND DEGRAD DEV.pdf available at https://authorea.com/users/395681/articles/ 508847-comparison-on-soil-organic-carbon-and-nitrogen-dynamics-between-urban-impervioussurfaces-and-vegetation 